\title{
Mechanical and Thermal Properties of Blends Based on Polyhydroxyalkanoates ${ }^{\dagger}$
}

\author{
Marius Stelian Popa 1, Irina Lupescu 2,3, Cristian Andi Nicolae 1, Augusta Raluca Gabor 1, \\ Adriana Nicoleta Frone ${ }^{1}$ and Denis Mihaela Panaitescu ${ }^{1, *}$ \\ 1 National Institute for Research \& Development in Chemistry and Petrochemistry-ICECHIM, 202 Spl. \\ Independenţei, 060021 Bucharest, Romania; popamarius7777@gmail.com (M.S.P.); \\ ca_nicolae@yahoo.com (C.A.N.); ralucagabor@yahoo.com (A.R.G.); ciucu_adriana@yahoo.com (A.N.F.) \\ 2 National Institute for Chemical Pharmaceutical Research and Development ICCF, 112 Calea Vitan, \\ 031299 Bucharest, Romania; irina.lupescu@spiruharet.ro \\ 3 Spiru Haret University, Faculty of Veterinary Medicine, 256 Basarabia Blvd., 030352 Bucharest, Romania \\ * Correspondence: panaitescu@icechim.ro \\ + Presented at the 16th International Symposium "Priorities of Chemistry for a Sustainable Development" \\ PRIOCHEM, Bucharest, Romania, 28-30 October 2020.
}

Published: 11 November 2020

Keywords: bioblends; polyhydroxyalkanoates; copolyesters; thermal analyses

Polyhydroxybutyrate (PHB) is a biodegradable and biocompatible thermoplastic polymer with good properties, similar to that of polypropylene, but with a higher price. In addition, it is very brittle and difficult to process by melting, which limits its usage [1-3]. To overcome these drawbacks, PHB is usually blended or copolymerized with other polymers [2,3]. In this study, PHB was blended with medium-chain-length polyhydroxyalkanoates (PHAs), which are elastomeric materials. For this purpose, two copolymers with different ratios of monomers, namely polyhydroxyoctanoate (PHO) and polyhydroxynonanoate (PHN), were added in $20 \mathrm{wt} \%$ in $\mathrm{PHB}$ using a melt processing technique. Neat PHB was purchased from Goodfellow; PHO, with a high fraction of $\mathrm{C} 8$, and $\mathrm{PHN}$, with a high fraction of $\mathrm{C} 9$, were obtained by microbial biosynthesis. The $\mathrm{PHB} / 20 \mathrm{PHO}$ and $\mathrm{PHB} / 20 \mathrm{PHN}$ blends were obtained via melt mixing in a Brabender Labstation at $160^{\circ} \mathrm{C}$, for $8 \mathrm{~min}$. The thermal characteristics of pristine PHB and blends were investigated via TGA and DSC, and thermomechanical characteristics via DMA. An increase in crystallinity was noticed in all the blends compared to plain PHB due to the nucleating effect of PHN and, especially PHO. A slight increase in the thermal stability was also observed in the blends due to the elastomeric nature of PHAs and improved processability. Moreover, the presence of longer side hydrocarbon chains in $\mathrm{PHO}$ and PHN increased the hydrophobicity of the blends (Figure 1). Importantly, the addition of elastomeric copolyesters in a concentration of up to $20 \%$ did not reduce the modulus of elasticity of PHB. 


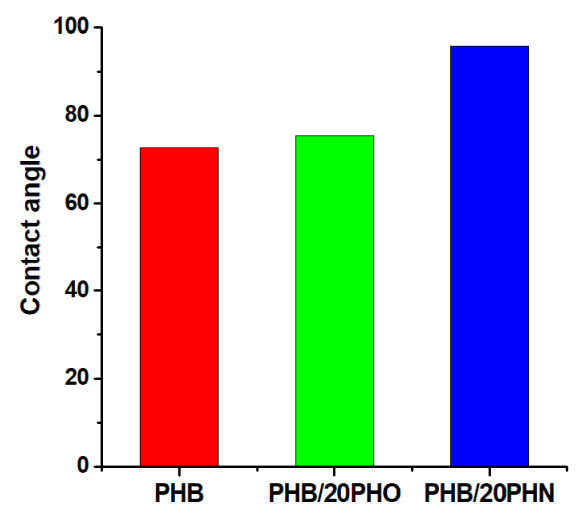

Figure 1. Water contact angles of polyhydroxybutyrate (PHB) and its blends.

This study revealed the importance of modifying highly brittle PHB with elastomeric PHAs in order to improve both flexibility and melt processability. In addition, the effect of PHAs with different compositions was highlighted in this study.

Acknowledgments: This work was supported by a grant of the Romanian Ministry of Research and Innovation, UEFISCDI project number PN-III-P1-1.2-PCCDI-2017-0428 (40/2018-Napoli19) within PNCDI III.

\section{References}

1. Kaplan, D.L. Biopolymers from Renewable Resources; Springer: Berlin, Gremany, 1998. ISBN 978-3540635673.

2. Panaitescu, D.M.; Frone, A.N.; Chiulan, I.; Nicolae, C.A.; Trusca, R.; Ghiurea, M.; Gabor, A.R.; Mihailescu, M.; Casarica, A.; Lupescu, I. Role of bacterial cellulose and poly (3-hydroxyhexanoate-co-3 -hydroxyoctanoate) in poly (3-hydroxybutyrate) blends and composites. Cellulose 2018, 25, 5569-5591.

3. Lukasiewicz, B.; Basnett, P.; Nigmatullin, R.; Matharu, R.; Knowles, J.C.; Roy, I. Binary polyhydroxyalkanoate systems for soft tissue engineering. Acta Biomater. 2018, 71, 225-234.

Publisher's Note: MDPI stays neutral with regard to jurisdictional claims in published maps and institutional affiliations.

2020 by the authors. Licensee MDPI, Basel, Switzerland. This article is an open access article distributed under the terms and conditions of the Creative Commons Attribution (CC BY) license (http://creativecommons.org/licenses/by/4.0/). 